\title{
BMJ Open Retrospective observational study of ethnicity-gender pay gaps among hospital and community health service doctors in England
}

\author{
Carol Woodhams (D) , ${ }^{1}$ Mark Williams (D) , ${ }^{2}$ Jane Dacre, ${ }^{3}$ Ira Parnerkar, ${ }^{1}$ \\ Mukunda Sharma ${ }^{4}$
}

To cite: Woodhams C, Williams M, Dacre J, et al. Retrospective observational study of ethnicity-gender pay gaps among hospital and community health service doctors in England. BMJ Open 2021;11:e051043. doi:10.1136/ bmjopen-2021-051043

- Prepublication history and additional supplemental material for this paper are available online. To view these files, please visit the journal online (http://dx.doi.org/10.1136/ bmjopen-2021-051043).

Received 09 March 2021 Accepted 08 November 2021

D) Check for updates

(c) Author(s) (or their employer(s)) 2021. Re-use permitted under CC BY-NC. No commercial re-use. See rights and permissions. Published by BMJ.

${ }^{1}$ Surrey Business School, University of Surrey, Guildford, UK

${ }^{2}$ School of Business and

Management, Queen Mary

University of London, London,

UK

${ }^{3}$ UCL Medical School, London,

UK

${ }^{4}$ Independent Researcher,

London, UK

Correspondence to

Dr Carol Woodhams;

C.Woodhams@surrey.ac.uk

\section{ABSTRACT}

Objectives To identify differences in average basic pay between groups of National Health Service (NHS) doctors cross-classified by ethnicity and gender. Analyse the extent to which characteristics (grade, specialty, age, hours, etc.) can explain these differences.

Design Retrospective observational study using repeated cross-section design.

Setting Hospital and Community Health Service (HCHS) in England.

Participants All HCHS doctors in England employed by the NHS between 2016 and 2020 appearing in the Digital Electronic Staff Record dataset (average $\mathrm{N}=99953$ per year).

Main outcome measures Hours-adjusted fulltime equivalent pay gaps; given as raw data and further adjusted for demographic, job, and workplace characteristics (such as grade, specialty, age, whether British nationality, region) using multivariable regression and statistical decomposition techniques.

Results Pay gaps relative to white men vary with the ethnicity-gender combination. Indian men slightly outearn white men and Bangladeshi women have a $40 \%$ pay gap. In most cases, pay gaps can largely be explained by characteristics that can be measured, especially grade, with the extent varying by specific ethnicity-gender group. However, a portion of pay gaps cannot be explained by characteristics that can be measured.

Conclusions This study presents new evidence on ethnicity-gender pay gaps among NHS doctors in England using high quality administrative and payroll data. The findings indicate all ethnicity-gender groups earn less than white men on average, except for Indian men. In some cases, these differences cannot be explained giving rise to discussions about the role of discrimination.

\section{INTRODUCTION}

Differences in earnings between men and women doctors and differences between white and non-white doctors are well known. An analysis of ethnicity pay gaps by the Nuffield Trust revealed a 'small' pay gap generally favouring white doctors in England. ${ }^{1}$ Additionally, the Independent Review into Gender
Strengths and limitations of this study

- This study considers differences in pay between ethnicity and gender groups after standardising differences in working hours for all hospital doctors in England.

- Statistical techniques explain differences in pay between these groups in terms of what we know about them, their careers and jobs.

- It does not consider other components of pay such as overtime and other premia.

- It does not consider how unmeasured factors such as productivity and the elongated career paths of international medical graduates contribute to pay.

- This study does not consider how barriers and discriminatory outcomes related to ethnicity and gender may contribute to differences in characteristics such as grade.

Pay Gaps in Medicine in England revealed that there was a gender pay gap in mean annual pay of $24.4 \%$ favouring men among Hospital and Community Health Service (HCHS) doctors in National Health Service (NHS) trusts in England, which reduces to $18.9 \%$ when expressed on a pro-rata basis. ${ }^{2}$ Given that women make up nearly half the medical workforce, ${ }^{3}$ it is disappointing that this is about twice as large as the gender pay gap for professional employees in the UK. ${ }^{4}$ The Review arguably represented the most detailed analysis ever of gender pay gaps in a profession. However, it did not explore the interaction between ethnicity and gender in detail. This paper aims to do so for HCHS doctors in NHS trusts in England.

Prior analyses have only considered gender and ethnic pay gaps additively. The different question of how combinations of ethnicity by gender groups compare to each other (ie, multiplicatively) has very rarely been explored in medicine. ${ }^{56}$ Pay gap patterns 
from defining groups in this way are often different from analysing ethnicity or gender separately. ${ }^{7}$ In the social science literature, this is referred to as intersectional inequalities ${ }^{89}$; that is pay gaps that relate to multiple overlapping identity categories, which in our case are ethnicity and gender. The term 'intersectionality' originated in the USA to describe how viewing social advantage and disadvantage along single and discrete axes was misleading. ${ }^{10}$ For instance, a recent analysis by the Bank of England on a nationally representative sample of all workers in the UK found that women earned less than men on average, although non-white men earned less than white men and non-white women earned more than white women. ${ }^{7}$ The main contribution we seek to make is to explore ethnicity-gender pay gaps among medics through the lens of 'intersectionality'. In foreshadowing the findings, given the exploratory nature of this paper we, have only general expectations. Following on from the intersectional perspective, we expect that stereotypes about cross-cutting categories of difference such as gender and ethnicities may advantage some groups and disadvantage others. ${ }^{611}$ We therefore expect the average pay disadvantage of women to vary according to ethnicity, and white men to generally be the highest earning group of all groups.

A second contribution we seek to make is to move beyond the simplistic two-factor view of ethnicity identity, which collapses non-white ethnicity groups into a single category of Black, Asian and Minority Ethnic ('BAME'). This is a pertinent issue in terms of pay gaps, because some non-white ethnicity subgroups experience slight pay advantages over white doctors. ${ }^{12}$ It is also especially pertinent to NHS HCHS doctors in England, where 44\% are 'BAME', ${ }^{13}$ four times more than the proportion in the UK labour market. ${ }^{14}$

An innovation of the Independent Review into Gender Pay Gaps in Medicine in England ${ }^{2}$ was to 'decompose' pay gaps into explanations that account for the differing composition of groups across pay bands on the one hand, and the differing wage structures of groups on the other. Our final contribution is to apply these techniques to the analysis of intersecting ethnicity-gender pay gaps to draw conclusions. We expect that the majority proportion of pay gaps of groups relative to white men will be explained by factors we can observe, for example, that groups are unequally distributed across grades and levels of seniority.

\section{METHODS}

The following is an analysis of ethnicity-gender pay gaps using data from all NHS trust doctors in the Electronic Staff Record (ESR). The study pooled cross-sectional data for 51 months from January 2016 to March 2020. Our data access included all doctors working in NHS trusts in England. We used ordinary least squares regression analysis combined with Oaxaca-Blinder decomposition techniques to delineate the causes of pay gaps.

\section{The ESR}

The ESR is an administrative monthly payroll dataset. It records a rich set of information about each doctor including earnings, demographic, job, and workplace characteristics. We used this data within a pooled repeated cross-section design to determine differences in average pay between ethnicity-gender groups. We excluded those with a non-medical primary area of work (eg, corporate, estates, dental/oral and facilities) from the sample. We included all grades (foundation years 1 and 2, staff and local grades, core trainees and specialty registrars, consultants, associate specialists and specialty doctors). We excluded cases where basic pay was zero or negative, where monthly hours worked were zero or exceed 320, and those with an inactive contract. Our final sample consisted of 5097897 doctor-month observations generated from 164820 individual doctors. The average number of doctors in the sample each year grew from 95 636 in 2016 to 108408 in 2020. To maintain representativeness of the sample, all doctors are included, irrespective of their length of service.

\section{Analysis}

To identify pay gaps, we followed the government's advice on gender pay gap reporting which defines the gender pay gap as the percentage difference in women's relative to men's mean earnings using hours-adjusted measures. Given our focus is on ethnicity-gender gaps, we took white men as the reference group, as they are usually the most advantaged.

To explore the extent to which average pay can be explained by observed characteristics (ie, characteristics that we have information about, see under the 'Measures' section), we used an ordinary least squares (OLS) regression decomposition technique known as Oaxaca-Blinder decomposition-see online supplemental appendix A-(henceforth OBD), ${ }^{15}{ }^{16}$ which is widely used in the econometric analysis of pay gaps ${ }^{17} 18$ and in health studies. ${ }^{19}{ }^{20}$ The OBD statistical technique decomposes a pay gap into two elements by deploying OLS regression techniques to illuminate how patterns in the composition of groups influence the gap. For example, one reason a pay gap emerges between two groups is because they are differently composed across, for example, grade, that is, one group is more likely to be found in higher-paid senior grades than the other. Pay also tends to increase with age (through accumulated experience and tenure) and surgery is the highest-paid specialty. All can be considered, on the face of it, legitimate reasons for pay gaps. The extent to which these compositional factors account for observed pay gaps is captured by 'endowment effects'. Pay gaps may also emerge because one group may get paid more on average for attaining a grade, holding other factors constant. The extent to which these wage structure factors adjust observed pay gaps are captured within 'coefficient effects'. Differing wage structures for a given set of characteristics can arise because, for example, groups consistently occupy lower 
points on pay scales for a given grade, or specialty, or age etc. Coefficient effects may therefore indicate discrimination or wage bias.

Given we use population and not sample data, we only report 95\% CIs in the text for estimated parameters (ie, those arising from the multivariable analysis focusing on the pooled sample).

\section{Measures}

Ethnicity is self-assigned in the ESR. Seventy-six ethnicity categories in the ESR were reduced to seven for the purposes of analysis: white, black, Indian, Pakistani, Bangladeshi, Chinese, including the South East Asian (SEA) group and mixed race. These were then crossclassified with gender to create 14 ethnicity-gender groups. The labels for these groups have been abbreviated in the figures to improve their legibility where $\mathrm{W}$ indicates women and $\mathrm{M}$ men. So, for example, blackW refers to black women and IndianM to Indian men.

The main dependent variable was basic monthly pay; that is the element of pay before overtime, bonuses and tax are applied. Because one reason why pay may vary between individuals and groups is differences in contracted hours, our findings adjusted basic monthly pay by contracted hours to create full-time equivalent pay. We also controlled for month and year fixed effects to account for inflation. Given the left skew in pay, we transformed pay using the natural logarithm. This transformation also had the added benefit for our purposes in exploring pay gaps because the coefficients in the multivariable analyses were roughly equivalent to percentage point differences.

A variety of explanatory factors for pay gaps were available in the ESR and were also included. Explanatory variables were classified into following categories: age (a proxy for career experience) and age squared (to account for non-linearities in age-earnings profiles). Grade was indicated in a set of binary indicators for senior doctors (consisting of consultants, associate specialists and specialty doctors) junior doctors (comprising of specialty registrars, core trainees and foundation year students) plus staff and local grade doctor. Specialty included binary indicators for primary area of work that is, clinical oncology, clinical support, general acute, imaging, medicine, surgery, obstetrics and gynaecology, psychiatry, pathology, public health and occupational health. Region is indicated by dividing the population into 10 strategic health authorities. Personal characteristics consisted of a comprehensive set of variables on nationality, religion, sexual orientation and disability status. Work-related characteristics included variables on whether each doctor held a fixed term contract or not, and whether there were multiple NHS assignments in a given person for the month.

\section{Patient and public involvement}

No patients were involved.

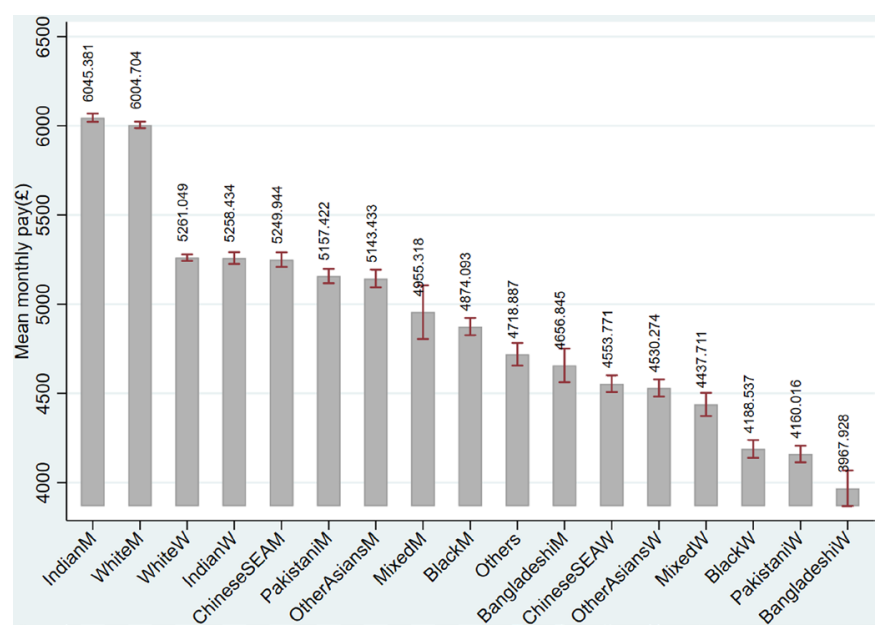

Figure 1 Mean monthly basic pay by ethnicity-gender March 2020.

\section{RESULTS}

\section{Descriptive overview}

In our population of 164820 total doctors, we found missing data either in the form of actual missing or refusal to divulge in the case of ethnicity for 11318 doctors (6.9\%) and nationality $(4812,2.9 \%)$. We also found substantial missing data in sexual orientation $(57752,34.0 \%)$ and religious identity (62 881, 38.1\%) categories. All other variables in the data had less than $0.1 \%$ missing observations. In the analysis, non-white doctors constituted $49.1 \%$. Non-white men and women comprised $31.1 \%$ and $18.0 \%$ of all doctors, respectively.

White doctors constituted the majority (50.9\%) followed by Indians (15.2\%), others/unknown (6.9\%), Chinese/SEA (6.5\%), Pakistanis (6.2\%), other Asians $(5.1 \%)$, blacks $(4.9 \%)$, mixed race $(3.3 \%)$ and Bangladeshis $(1.0 \%)$. In terms of ethnicity gender, white women constituted the largest group $(25.8 \%)$ followed by white men $(25.1 \%)$, Indian men $(9.2 \%)$, Indian women $(6.1 \%)$, Chinese/SEA men $(3.8 \%)$ and Pakistani men (3.6\%).

To commence the analysis in relation to the first study objective, we explored differences in basic monthly pay among detailed intersectional ethnicity-gender categories (figure 1) and tracked them over 5 years (figure 2). Both figures illustrate the importance of disassembling the 'BAME' category by showing considerable pay gap heterogeneity by ethnic and gender group. All ethnicitygender groups earned less than white men, except for Indian male doctors who earned slightly more. There were especially large gaps for Bangladeshi, Pakistani, black, mixed race and Chinese/SEA women doctors, who experienced on average between $25 \%$ and $40 \%$ lower pay than white men, amounting to a monthly basic pay gap of around $£ 1500-£ 2000$. White women and Indian women received lower pay relative to white men in similar magnitude to the disadvantages experienced by Chinese/SEA men, Pakistani men and black men, with these groups experiencing around 10\%-20\% lower pay on average. Bangladeshi men were noticeably the most disadvantaged male category, earning on average approximately $20 \%$ 


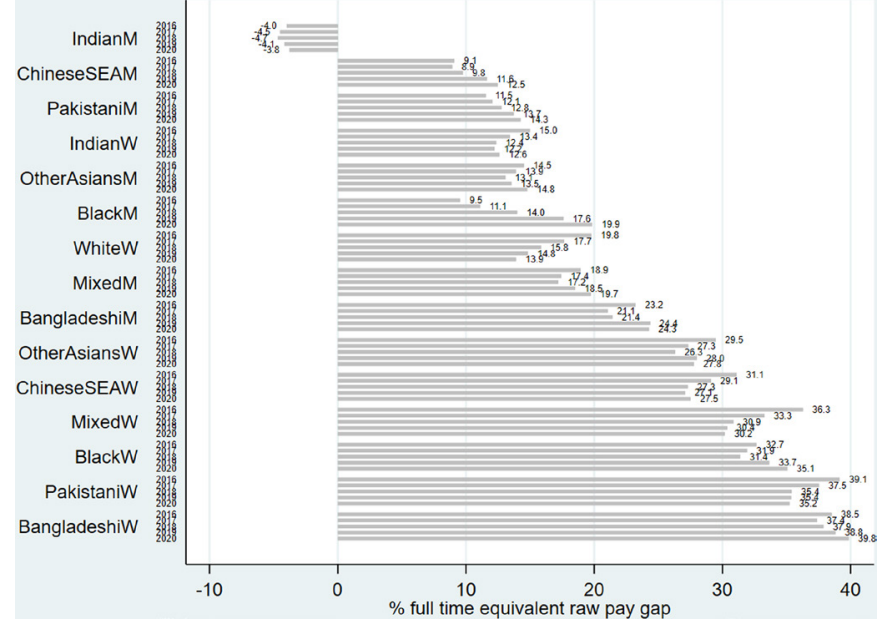

Figure 2 Pay gaps in mean monthly pay relative to white men 2016 to 2020. SEAW, South East Asian women.

less than white men. Over the 5 years of measurement, pay gaps for most groups remained high, but did not increase. The exception to this was pay gaps for Chinese/ SEA men, black men and Pakistani men which grew steadily by $3.4 \%, 10.3 \%$ and $3.5 \%$, respectively.

\section{Decomposition analysis: explaining pay gaps}

To address the second study objective and determine the extent to which differences in the composition of ethnicity-gender groups and their wage structures accounted for pay gaps relative to those of white men, we undertook an OBD decomposition using all explanatory factors in the ESR. The results are presented in figures 3 and 4 . Figure 3 presents a decomposition of pay gaps relative to white men in absolute terms, summing to the mean pay gap for each group with a percentage point interpretation. Figure 4 presents the same but in relative terms, where the contribution of endowments and coefficient effects can be compared across groups and sum to $100 \%$.

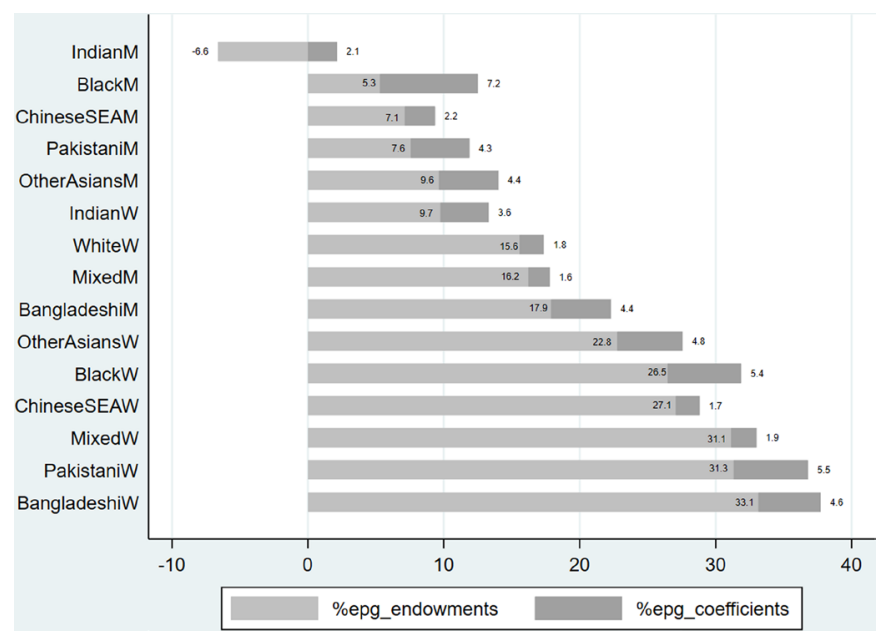

Figure 3 Decomposition of pay gaps, absolute contribution of endowment and coefficient (\% points). SEAW, South East Asian women.

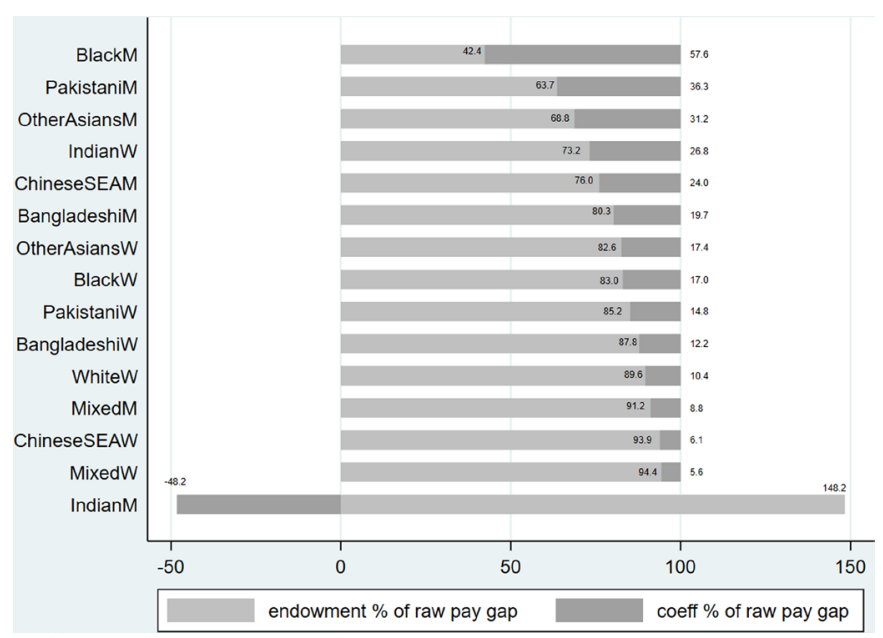

Figure 4 Decomposition of pay gaps, relative contribution of endowment and coefficient effects (\%). SEAW, South East Asian women.

The main finding from this figure is that for almost all groups, differences in endowments accounted for about two-thirds or more of the pay gap with white men. This means that, in most cases, the major proportion of each pay gap was explained by known factors (figure 5). These factors were especially important in the case of Bangladeshi, Pakistani, black, mixed race and Chinese/SEA women doctors where the pay gap was large but can be explained by differences in endowments. The exception here was black men doctors, where endowment effects accounted for only two-fifths of their pay gap.

The coefficient effect, which could be held to be evidence of direct pay discrimination, was a feature for all groups, and notably large for black men and women. In relative terms, the coefficient effect tended to be larger for the male categories, especially black men where it explained $57.6 \%$ of the pay gap $(56.0 \%-59.1 \%)$, and for Indian men (who earn slightly more than white men) where it offset their seeming endowment advantage by $48.2 \%(50.6 \%-45.9 \%)$. However, a wide array of other unmeasured characteristics such as productivity, performance or work histories can also determine basic pay, so we are cautious in using this interpretation. For instance, although we included nationality as a control in our regression models, the ESR dataset does not include information on routes into training and employment. International medical graduates (IMG) and European Economic Area doctors tend to have longer training routes than UK-trained doctors to reach senior grades and this can be misattributed as ethnicity effects. However, we highlight that the wage structure effects uncovered here constitute an area for further, and urgent, investigation.

Finally, using decomposition techniques again, we disaggregated the most influential factors within the endowment element of the pay gap. In figure 5, we show that, all else being equal, grade consistently stood out as being the single most important factor, accounting for $40 \%-60 \%$ of pay gaps for all ethnicity-gender groups relative to white 

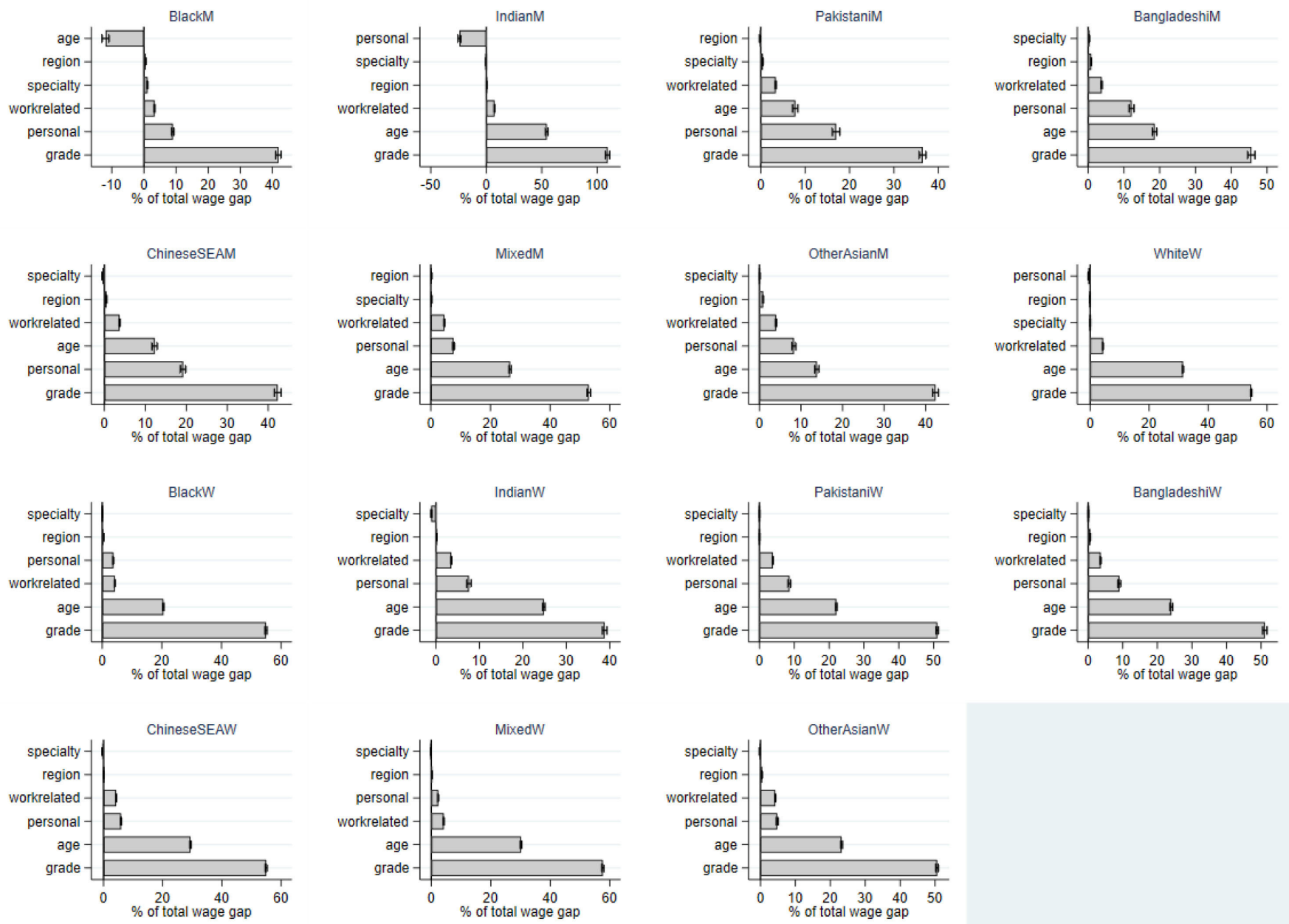

Figure 5 Absolute contribution of detailed endowment effects to pay gaps relative to white men (\% points). SEAM, South East Asian men.

men (see also table 1 below). Age was also important in explaining pay gaps with older doctors earning more on average. In the male ethnic doctor categories, its contribution to the pay gap was minor for many, for example, $7.8 \%(7.2 \%-8.4 \%)$ for Pakistani men. Since black men were, on average, older than white men (43.5 vs 42.5 ) this reduced their pay gap by $11.9 \%(13 \%-10.9 \%)$. For all female categories, the contribution of age to the pay gap varied between $20 \%$ and $30 \%$. Specialty played a very minor role in the pay gap, explaining less than $1 \%$ for any group. Region and work-related variables had almost no influence.

The contribution of personal features to pay gaps is worth noting. As a group, Indian men were distributed across personal feature measures (nationality, religion, sexual orientation and disability status) in ways that were well-rewarded and reduced their pay gap by $24.1 \%$ $(25.4 \%-22.9 \%)$. Personal features, however, disadvantaged other groups of ethnic minority men, explaining $12.1 \%(11.4 \%-12.8 \%), 17 \%(16.2 \%-17.8 \%)$ and $19.2 \%$ $(18.5 \%-19.9 \%)$ of the pay gap for Bangladeshi, Pakistani and Chinese and SEA men, respectively. Personal features had a smaller, but still statistically significant, impact on the pay gaps of ethnic minority women, accounting for $5.9 \%(5.8 \%-6.1 \%), 7.6 \%(7.1 \%-8.1 \%), 8.6 \%(8.2 \%-9 \%)$ and $9 \%(8.6 \%-9.4 \%)$ of the pay gap for Indian, Bangladeshi, Pakistani and Chinese and SEA women, respectively. Work-related variables which include contract type (permanent vs fixed-term) and number of assignments played a minor, but also statistically significant, role in pay gaps, explaining between $3 \%$ and $4 \%$ of the total pay gap for most men and women with the exception of Indian men where they explained $7.4 \%(7.1 \%-7.6 \%)$.

To reinforce our understanding of why grade and age are important to the observable (endowment) pay gaps between ethnicity-gender categories relative to white men, we show the distributions of these factors by ethnicity-gender.

White men had among the highest mean age and were disproportionately found in senior ranks. Indian men were also favourably distributed across grade and age, but their advantage was mitigated by the coefficient effect explored above. The lowest-paid ethnicity-gender groups were less likely to be observed in senior grades. For instance, Chinese/SEA women, mixed race women, black women, Pakistani women and Bangladeshi women 
Table 1 Composition of ethnicity-gender groups

\begin{tabular}{lll}
\hline & Age (mean) & $\begin{array}{l}\text { Senior doctors' grade } \\
\text { (\% ethnicity gender) }\end{array}$ \\
\hline WhiteM & 42.5 & 60.7 \\
\hline BlackM & 43.5 & 49.5 \\
\hline IndianM & 43.5 & 67.7 \\
\hline PakistaniM & 41.6 & 51.5 \\
\hline BangladeshiM & 39.0 & 42.3 \\
\hline ChineseSEAM & 41.7 & 52.6 \\
\hline MixedM & 38.9 & 44.3 \\
\hline OtherAsiansM & 41.1 & 49.5 \\
\hline WhiteW & 38.3 & 45.0 \\
\hline BlackW & 37.5 & 31.1 \\
\hline IndianW & 39.5 & 50.8 \\
\hline PakistaniW & 36.4 & 29.0 \\
\hline BangladeshiW & 35.8 & 28.5 \\
\hline ChineseSEAW & 36.4 & 34.3 \\
\hline MixedW & 35.4 & 29.9 \\
\hline OtherAsianW & 37.7 & 37.3 \\
\hline
\end{tabular}

SEAM, South East Asian men; SEAW, South East Asian women.

were half as likely to be in senior grades relative to white men (around 30\% vs 60\%). These groups also tended to be younger.

\section{DISCUSSION}

To the best of our knowledge, this study represents the first 'intersectional' analysis of basic pay gaps among HCHS doctors in England relative to white men. As well as identifying these gaps, we also applied multivariable decomposition techniques widely used in pay gaps research and the recent Independent Review into Gender Pay Gaps in Medicine in England. Extending the findings in the Review, we find evidence of pay disadvantage particularly for all groups of women doctors, but with white men as the reference category, we find pay disadvantage for most non-white men too.

Importantly, we find that there is much heterogeneity in pay gaps across groups. Large gaps are found for Bangladeshi, Pakistani, black, mixed race and Chinese/ SEA women. White women and Indian women suffer from lower pay relative to white men in a magnitude similar to the disadvantages experienced by Chinese/SEA men, Pakistani men and black men. Bangladeshi men are noticeably the most disadvantaged male category. Only Indian men earn similarly to white men on average.

One innovation of the Review was employing multivariable decomposition techniques to explain the factors that account for pay gaps between groups. Applying these techniques to ethnicity-gender pay gaps relative to white men, demonstrates that most gaps (except for Black men) can be accounted for by observed factors, with grade differences explaining the majority. The predominance of white men in senior ranks perpetuates the gap and this will need to be overcome if pay gaps are to reduce. ${ }^{5}$ White men are also, on average, older, which goes some way towards explaining their higher earnings. However, for most groups, the disadvantageous role of personal features such as religion, sexuality and nationality in pay gaps requires investigation. Plus, a disadvantaging if small, in absolute terms, coefficient effect is found for all groups, indicating that they are paid less than white men for the same characteristics that we observe in the ESR (grade, specialty, age, etc). This accounts for a larger share for male category doctors, especially black, Pakistani and Indian men, explaining more than a third of their pay gap. There is a possibility that these effects might, all else being equal, result from the differentiated allocation of opportunities for progression or valueenhancing experience, such as committee memberships, among homophilous networks especially in senior ranks. The differing wage structures between ethnicity-gender groups for a given set of characteristics certainly warrants urgent further investigation.

\section{Implications of the findings}

The Review highlighted the gender dimension of unsympathetic career structures as an important factor in understanding the gender pay gap. ${ }^{2}$ This study used the same methodology to understand differences in full-time equivalent mean pay for intersectional groups. Implications of this study highlight, first, the importance of disaggregating the workforce into intersectional groups as the success of one group (Indian male doctors) can obscure the extraordinary disadvantage of others (eg, Bangladeshi women). Second, via decomposition analysis we have highlighted the importance of overcoming pay gaps for all intersectional groups by working towards the goal of equalising grade via equal progression and building equal workplace experience by ensuring improved workforce retention relative to white men. A focus of workforce policy directed towards alleviating pay gaps should be to better understand why there is uneven progression through the grades between ethnicity-gender groups, especially the female groups ${ }^{21}$ plus targeting them with retention strategies. We find that specialty choice was not particularly important in understanding pay gaps, however, strategies of making high prestige specialties a more attractive medical career option for women and especially minority ethnic women would also pay dividends where they are needed.

Findings also revealed that even when accounting for grade and other compositional differences, certain groups appear to be paid less, on average, for these characteristics. Coefficient effects account for the majority of the pay gap for black men and more than one-third of the pay gap relative to white men in other cases. As we have stressed, the evidence presented here cannot be straightforwardly interpreted as pay discrimination, but the findings do demand further research into why certain groups 
are paid differently for the same characteristics, such as grade and specialty. For all the detail we achieve, we still only present a broad portrait here.

\section{Limitations}

There are several limitations to this study. First, we only focused on basic pay. Basic pay measures do not include overtime, CEAs, shift work premia, etc. The Review identified these non-basic components of pay as important contributing factors to the total gender pay gap among HCHS doctors, with gender gaps being larger for total pay than for basic pay. Moreover, in the Review, observed characteristics were even less able to explain non-basic components of pay. It is likely therefore that we have underestimated the full extent of intersectional disparities.

Second, we only focused on monthly pay, not annual pay, meaning gaps may be understated for groups that are more affected by absences or short contract working. Third, while we included a rich set of explanatory variables in our analyses, there are always other factors that determine pay and so differences in average pay between groups. Statistically, the balance between endowment and coefficient effects in accounting for pay gaps depends on the variables included into the model, with, in general, the inclusion of more variables increasing the proportion of pay gaps explained. There are a variety of work history factors including IMG doctor status that could be explored, if captured in the ESR. There are other unmeasured factors that may affect pay but have no straightforward means to be robustly explored, such as within-grade salary point, productivity and performance. Other unmeasured factors could include pay discrimination. Factors such as these may well account for the disadvantaging wage structure effects that were observed, but further research is clearly needed to understand them.

\section{CONCLUSIONS}

Differences in pay between men and women and white and non-white doctors are well known. Pay gaps in medicine have been raised as a concern across other national contexts. ${ }^{2-24}$ Although the demographic make-up of 'minority' and disadvantaged groups will alter across national contexts, it is likely that similar compositional differences will create similar intersectional pay gaps.

Previous analysis of doctors in England has not explored the interaction between ethnicity identity and gender in understanding pay gaps. This study considered pay gaps in mean basic monthly pay between detailed ethnicitygender groups relative to white men for HCHS doctors in England. It applied multivariable decomposition techniques to explain pay gaps. Findings reveal non-white doctors earn less than white doctors on average, but there is much heterogeneity in the magnitude of pay gaps, with certain female ethnic groups being particularly disadvantaged. Much of the pay gap relative to white men can be explained by differing composition of groups, especially in terms of age grade, but all groups suffer at least a small disadvantaging pay penalty not accounted for by observed characteristics.

Finally, we are keen to stress that explaining pay gaps between groups using compositional differences does not justify them. Statistical models employed here cannot account for structural barriers and discrimination that led to the differences in composition between groups in the first place (eg, achieving a certain level of seniority for a given age). Supplementing statistical analysis with robust qualitative evidence will help to elucidate how this occurs.

\section{Twitter Mark Williams @DrMTWilliams}

Acknowledgements We would like to acknowledge the support of staff at the Department of Health and Social Care; Tim Sands, Miranda Worthington, Katie Kennington, Emma 0' Kerry and Rhiannon Metcalfe. Also, Kieron Walsh and the ESR team in the NHS Business Services Authority.

Contributors CW acts as guarantor. CW is involved in: conceptualisation, data curation, funding acquisition, investigation, methodology, project administration, resources, formal analysis, supervision, software, writing-original draft and writing-review and editing. MW is involved in: conceptualisation, investigation, methodology, formal analysis, supervision, software, writing-original draft and writing-review and editing. JD is involved in: conceptualisation, data curation, resources, validation, writing-original draft and writing-review and editing. IP is involved in: conceptualisation, formal analysis, investigation, methodology, validation, visualisation, writing-original draft and writing-review and editing. MS is involved in: conceptualisation, formal analysis, investigation, methodology, validation, visualisation, writing-original draft and writing-review and editing. Data are accessed and verified by CW, IP and MS.

Funding This research was funded by the Department of Health and Social Care (ITT 118).

Competing interests None declared.

Patient consent for publication Not applicable.

Provenance and peer review Not commissioned; externally peer reviewed.

Data availability statement Data may be obtained from a third party and are not publicly available. The data for the original study was supplied by the Department of Health and Social Care and cannot be shared.

Supplemental material This content has been supplied by the author(s). It has not been vetted by BMJ Publishing Group Limited (BMJ) and may not have been peer-reviewed. Any opinions or recommendations discussed are solely those of the author(s) and are not endorsed by BMJ. BMJ disclaims all liability and responsibility arising from any reliance placed on the content. Where the content includes any translated material, BMJ does not warrant the accuracy and reliability of the translations (including but not limited to local regulations, clinical guidelines, terminology, drug names and drug dosages), and is not responsible for any error and/or omissions arising from translation and adaptation or otherwise.

Open access This is an open access article distributed in accordance with the Creative Commons Attribution Non Commercial (CC BY-NC 4.0) license, which permits others to distribute, remix, adapt, build upon this work non-commercially, and license their derivative works on different terms, provided the original work is properly cited, appropriate credit is given, any changes made indicated, and the use is non-commercial. See: http://creativecommons.org/licenses/by-nc/4.0/.

\section{ORCID iDs}

Carol Woodhams http://orcid.org/0000-0002-9703-1107

Mark Williams http://orcid.org/0000-0002-4108-0583

\section{REFERENCES}

1 Appleby J. What is the ethnicity pay gap among NHS doctors? 2018. Available: https://www.nuffieldtrust.org.uk/news-item/what-is-theethnicity-pay-gap-among-nhs-doctors [Accessed 15 Jan 2021].

2 Dacre J, Woodhams C, Atkinson C. Mend the gap: the independent review into gender pay gaps in medicine in England. London: Department of Health and Social Care, 2020. 
3 General Medical Council (Great Britain). The state of medical education and practice in the UK. General Medical Council, 2020.

4 Smith R. Gender gap in the UK. London: Office for National Statistics, 2020. https://www.ons.gov.uk/employmentandlab ourmarket/peopleinwork/earningsandworkinghours/bulletins/ genderpaygapintheuk/2020

5 Milner A, Baker E, Jeraj S, et al. Race-ethnic and gender differences in representation within the English National Health Service: a quantitative analysis. BMJ Open 2020;10:e034258.

6 Samra R, Hankivsky O. Adopting an intersectionality framework to address power and equity in medicine. Lancet 2021;397:857-9.

7 Amadxarif Z, Angeli M, Haldane A. Understanding pay gaps. Working paper 877 Bank of England, 2020. Available: https://www. bankofengland.co.uk/

8 Acker J. Inequality regimes: gender, class, and race in organizations. Gender \& Society 2008;20:441-64.

9 Walby S, Armstrong J, Strid S. Intersectionality: multiple inequalities in social theory. Sociology 2012;46:224-40.

10 Crenshaw K. Demarginalizing the intersection of race and sex: a black feminist critique of antidiscrimination doctrine, feminist theory and antiracist politics. U Chi Legal f 1989;139.

11 Ridgeway CL, Kricheli-Katz T. Intersecting cultural beliefs in social relations: gender, race, and class binds and freedoms. Gender \& Society 2013;27:294-318.

12 Longhi S, Brynin M. The ethnicity pay gap. equality and human rights Commission, 2017. Available: https://www.equalityhumanrights.com/ en/our-research/list-all-our-research-reports

13 NHS Workforce Statistics, 2019. Available: https://www.ethnicityfacts-figures.service.gov.uk/workforce-and-business/workforcediversity/nhs-workforce/latest\#by-ethnicity-and-type-of-role [Accessed 15 Jan 2021].
14 Evans T. Ethnicity pay gaps in Great Britain: 2018, office for national statistics, 2019. Available: https://www.ons.gov.uk/employmentan dlabourmarket/peopleinwork/earningsandworkinghours/articles/ethn icitypaygapsingreatbritain/2018 [Accessed 15 Jan 2021].

15 Oaxaca R. Male-female wage differentials in urban labor markets. Int Econ Rev 1973;14:693-709.

16 Blinder AS. Wage discrimination: reduced form and structural estimates. J Human Res 1973;1:436-55.

17 Elder TE, Goddeeris JH, Haider SJ. Unexplained gaps and OaxacaBlinder decompositions. Labour Econ 2010;17:284-90.

18 Piazzalunga D, Di Tommaso ML. The increase of the gender wage gap in Italy during the 2008-2012 economic crisis. J Econom Inequal 2019;17:171-93.

19 O'Donnell O, Van Doorslaer E, Wagstaff A. Decomposition of inequalities in health and health care. In: In the Elgar companion to health economics. 2nd edn. Edward Elgar Publishing, 2012.

20 Sen B. Using the Oaxaca-Blinder decomposition as an empirical tool to analyze racial disparities in obesity. Obesity 2014;22:1750-5.

21 NHS Digital. Narrowing of NHS gender divide but men still the majority in senior roles, 2018. Available: https://digital.nhs.uk/newsand-events/latest-news/narrowing-of-nhs-gender-divide-but-menstill-the-majority-in-senior-roles [Accessed 16 Jan 2021].

22 Roy B. Gender pay gaps in medicine: moving from explanations to action. J Gen Intern Med 2018;33:1413-4.

23 Sin I, Bruce-Brand B. Is the pay of medical specialists in New Zealand gender biased? 2019. Available: https://www.asms.org.nz/ wp-content/uploads/2019/11/19-21-Gender-wage-gap-in-medicalprofessionals.pdf [Accessed 2 Feb 2021].

24 Schurer S, Kuehnle D, Scott A, et al. A man's blessing or a woman's curse? The family earnings gap of doctors. J Econ Soc 2016;55:385-414. 